\title{
Unremarkable but Crucial: Motivating Employees in Business as Usual Work
}

\author{
Matthias Cheong \\ School of Business, University of Western Australia. \\ Email: matthias.cheong@gmail.com
}

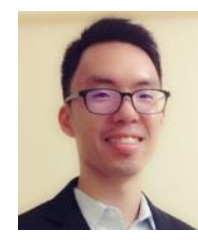

\section{Abstract}

'Business as usual' (BAU) tasks refers to the daily, mundane but necessary operational tasks performed by companies both large and small. While technology and automation have gone a large way towards reducing its necessity, some tasks still need to be performed by a human. Employees have typically shunned such roles as uninteresting, unrewarding, and unlikely to lead to career growth or recognition within the company. This in turn leads to low levels of motivation when performing such tasks, giving rise to a greater risk of mistakes being made, poor performance, or turnover as employees shun such work. This paper examines one typical team in the Singapore finance industry, highlighting the difficulties of motivating employees in performing such unremarkable but crucial tasks, and proposing some possible solutions that may be adopted. It is hoped that this article will give some insight to line managers in how to motivate employees to perform unremarkable but crucial BAU tasks.

Keywords: Motivation, Management, Employee performance, Retention, Work satisfaction, Organisational behaviour. JEL Classification: M19, F23, J24.

Citation | Matthias Cheong (2020). Unremarkable but Crucial: Motivating Employees in Business as Usual Work. Asian Journal of Social Sciences and Management Studies, 7(1): 34-38.

\section{History:}

Received: 24 December 2019

Revised: 20 January 2020

Accepted: 27 February 2020

Published: 6 April 2020

Licensed: This work is licensed under a Creative Commons

Attribution 3.0 License (cc)

Publisher: Asian Online Journal Publishing Group
Funding: This study received no specific financial support.

Competing Interests: The author declares that there are no conflicts of interests regarding the publication of this paper.

Transparency: The author confirms that the manuscript is an honest, accurate, and transparent account of the study was reported; that no vital features of the study have been omitted; and that any discrepancies from the study as planned have been explained.

Ethical: This study follows all ethical practices during writing.

\section{Contents}

1. Introduction

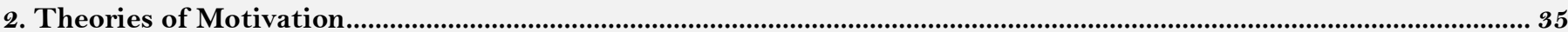

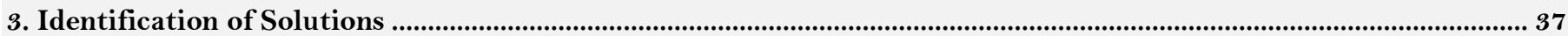

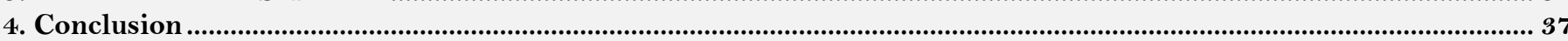

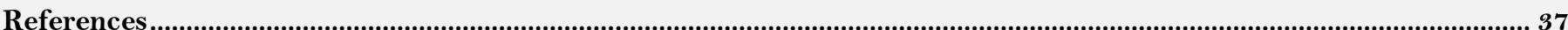




\section{Contribution of this paper to the literature}

This paper examines one typical team in the Singapore finance industry, highlighting the difficulties of motivating employees in performing such unremarkable but crucial tasks, and proposing some possible solutions that may be adopted.

\section{Introduction}

This paper highlights the present problem of a lack of motivation in performing Business as Usual (BAU) within a Team at a company. This could potentially hamper operational productivity. Motivational theories, applied correctly, could offer a solution to the problem. This paper outlines three possible theories - (a) Expectancy Theory, (b) Cognitive Evaluation Theory, and (c) Self-Determination Theory, and explores the feasibility of each. This paper then concludes by highlighting Self-Determination Theory as the most appropriate and applicable one, as it allows for the employees' need of autonomy, relatedness and competency to be met, thus facilitating an integrated regulation that should see an increase in motivation for BAU work.

\subsection{Background}

The Company under study is a global provider of information and analytics. One of the Company's core product is the Credit Derivative Swaps (CDS) pricing data, which helps customers make better decisions in gauging the creditworthiness of companies. The CDS pricing data team in Asia-Pacific consists of four personnel between the ages of 24 to 29 years old. Two employees are based in India and two are based in Singapore.

\subsection{The Problem}

A recent June 2019 Employee Engagement Survey (EES) points to a lack of motivation in the Company's AsiaPacific CDS Team. The results of the EES showed that:

- $75 \%$ of employees believed that they do not feel they were learning and growing.

- $50 \%$ of employees believed that they do not have good career opportunities at the firm.

The second indicator is that the voluntary employee turnover rate in the team had jumped to $50 \%$ in both India and Singapore in 2018. This is above the financial services industry's average voluntary attrition rate of $18.7 \%$ in India (KPMG, 2018) and 10\% in Singapore (Half, 2018). The third indicator is that in the employees' exit interviews, they mentioned that spending $70 \%$ of their time on BAU work was a key factor for them to leave the firm. They cited that greater exposure to client interaction, having more time to lead projects and write credit research articles would have incentivised them to stay with the firm. The results of the employee engagement survey and employees' exit interviews echoed the findings of a PricewaterhouseCoopers survey which found that $29 \%$ of millennials wanted more opportunities for personal development (PwC, 2012).

The consequences of employee resignations include disruptions to existing operations, delays in planned projects and additional time spent to hire and train the employee's replacement. This loss is estimated to cost between $50 \%$ to $150 \%$ of the employee's annual salary (Sujansky \& Ferri-Reed, 2009). Addressing the root cause of the lack of motivation is thus crucial to the Team's continued growth and operations.

Part of the low levels of employees' motivation can be attributed to the perception that client facing, trading and investment related roles are more desirable (Butcher, 2015). Although BAU work may seem repetitive and mundane compared to these jobs, it is hoped that the application of relevant organisational behaviour theories such as expectancy theory (Vroom, 1964) and self-concordance theory (Sheldon et al., 2004) can help to increase employees' motivation levels.

\subsection{Understanding the Root Causes}

The employees' expressed their concerns at a feedback session conducted subsequent to the EES. In the exit interviews with departing employees, the manager found that these employees mentioned that spending $70 \%$ of their time on BAU work was a key factor for them to leave the firm. They felt that they were not learning new skills on the job. They cited that they had no choice but to perform the BAU tasks as these are specified as key performance indicators in the quarterly performance appraisals. They found these tasks to be uninteresting and repetitive. Monitoring of file deliveries and price publications to client is a tedious and mundane job.

Their first concern was they did not feel they were learning new skills by performing repetitive BAU work such as performing data quality checks on CDS prices. Employees stated that they performed BAU work to avoid a negative performance appraisal. Their second concern was they felt micromanaged because of frequent reminders from the manager to perform BAU work. Their third concern was the reprimands for making mistakes in BAU work and the lack of praise when they performed BAU work satisfactorily. They felt that management does not recognize them for doing BAU tasks as much as work on other more visible projects. This then tends to lead to decreased growth and promotional opportunities for them. This created a situation of high risk for low reward and they were worried about their career opportunities at the firm.

\section{Theories of Motivation}

This paper examines three organisational theories from the existing literature - Expectancy Theory (ET: (Vroom, 1964) Cognitive Evaluation Theory (CET: (Deci, 1975)) and Self-Determination Theory (SDT: (Edward \& Ryan, 1985) and analyses how an application of these theories can increase employees' motivation levels in respect of BAU work.

\subsection{Expectancy Theory}

ET states that individuals are more likely to do a task well if they perceive the possibility of the reward to be high and is appealing (Vroom, 1964). The Porter and Lawler Model further suggested that employees will be more motivated to perform a task if the task was redesigned to be more interesting and that there are clear connections to link higher salary and promotions to the performance of the task (Porter \& Lawler, 1968). One main assumption 
in Porter and Lawler Model is that the overall job satisfaction is based on the accretive effects of intrinsic and extrinsic rewards. In the present context, ET suggests that the employees are more likely to do BAU work well if there is the possibility of higher financial remuneration and/or a promotion that comes with a good performance appraisal.

However, there are limits in applying ET at to the Team. It will be difficult to justify why the firm should increase the salary of employees just for continuing to do the same job. This is because the firm will most likely perceive there to be minimal additional value that the employees had provided for doing the same task.

Separately, one study found that material rewards reduced intrinsic motivation levels in individuals while intangible rewards such as praise enhanced intrinsic motivation (Deci, 1971). This further explains why using compensation and promotions may instead reduce the employees' motivation to do BAU work. As such, while ET may offer some benefits, its application to the present problem within the Team is limited.

\subsection{Cognitive Evaluation Theory}

The findings in Deci (1971) ET study led to the development of CET (Edward, Cascio, \& Krusell, 1975). Cognitive evaluation theory proposes that deadlines (Amabile, DeJong, \& Lepper, 1976) is more likely to lead to perceived lower autonomy, reducing intrinsic motivation. Other extrinsic motivators such as providing choices increases intrinsic motivation (Zuckerman, Porac, Lathin, \& Deci, 1978). CET posits that there are three kinds of motivation - (i) amotivation, (ii) extrinsic motivation, and (iii) intrinsic motivation. While material rewards may increase extrinsic motivation, it also reduces intrinsic motivation in individuals as performance of the task is attributed to their desire to obtain the reward and not from their internal need of competence and autonomy.

A study demonstrated that praise enhanced intrinsic motivation while tangible rewards reduced it Dec, Koestner, and Ryan (1999). CET thus explains that employees lack motivation while performing BAU work as they feel micromanaged and are not acquiring new skills. This reflects their unmet need for autonomy and competency. The lack of positive feedback from the manager and fear of negative performance appraisals appear to have decreased the employees' intrinsic motivation.

However, as discussed by Gagné and Deci (2005) there are limitations to applying CET in to the modern-day corporate firm, where employees' remuneration are pegged to the value of the work they perform. This increases extrinsic motivation while decreasing intrinsic motivation. Therefore, the use of pecuniary rewards as a mechanism to increase motivation for BAU work is not ideal as it merely increases an employee's extrinsic motivation while not addressing the employee's intrinsic motivation. This problem is further compounded by the nature of BAU work being mundane. This therefore restricts the manager's options for increasing intrinsic motivation, as there is limited scope make BAU work more 'interesting'. Additionally, while CET appears to suggest mere positive feedback is enough to increase intrinsic motivation, CET has been further developed into SDT, which offers a more nuanced approach and complete theory of intrinsic and extrinsic motivation.

\subsection{Self-Determination Theory}

SDT posits that if an individual's needs of autonomy, relatedness and competence are met, the individual is likely to internalize a behaviour and its underlying values (Deci \& Ryan, 2000; Edward. \& Ryan, 1985). SDT states that self-determination is a continuum ranging from amotivation to extrinsic motivation (which is further broken down into four types: external, introjected, identified and integrated regulation) to intrinsic motivation:

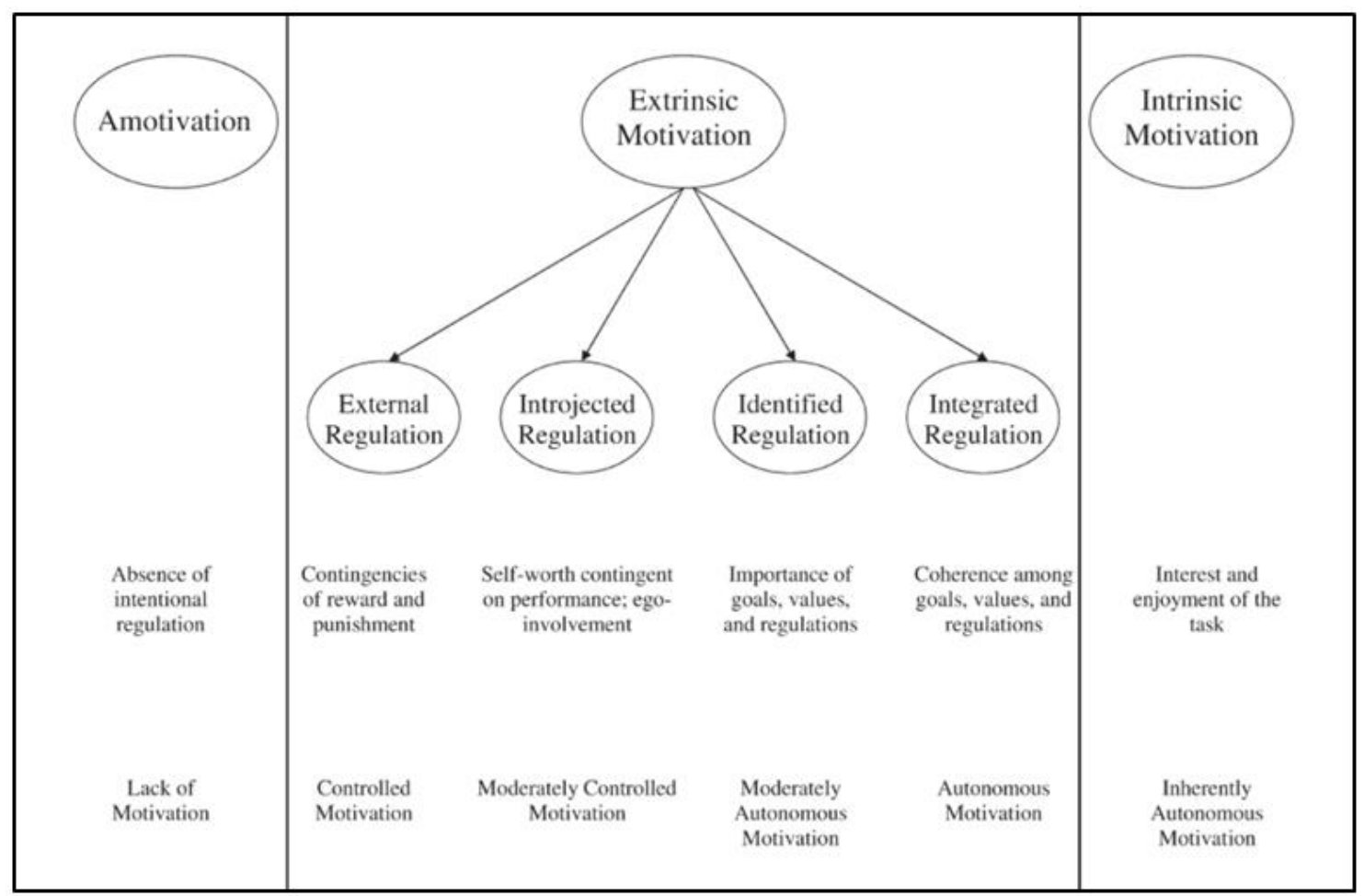

Source: Gagné and Deci (2005).

Figure-1. The self-determination continuum.

As illustrated in Figure 1 above, intrinsic motivation refers to an inherent autonomous motivation on part of the individual, where they are truly interested and enjoy the task. This means being motivated from one's interest in an activity (Gagné \& Deci, 2005) and as such, is arguably difficult to induce by virtue of external motivational devices. The closest to this state that can practically be achieved by a manager, is possibly integrated regulation. It is therefore this state that the proposes in the hopes of achieving this with the Team. 
A study confirmed that when parents provided their children with a supporting environment to meet their need of autonomy, relatedness and competence, the children were more likely to internalize school-related behaviour resulting in higher grades (Grolnick \& Ryan, 1989). Another study involving employees in Bulgaria and United States found that employee satisfaction improved when their need for competence, autonomy and relatedness were addressed at work (Deci et al., 2001). Applying SDT to the present context, it is likely that the employees' need for autonomy, relatedness and competence are unmet as they feel they are being micromanaged, and they believe that they are not learning new skills. Therefore, the employees are likely to have not fully internalized the behaviour of performing BAU work.

Another study found that providing a meaningful reason for performing a task, acknowledging that the task is uninteresting, and providing choices resulting in individuals wholly integrating a regulated behaviour as their own (Deci, Eghrari, Patrick, \& Leone, 1994). In this same study, the researchers also noted that if there were at least two out of three needs were met, individuals were more likely to internalize the behaviour; if less than two out of three needs were met, the individuals were more likely to display introjected motivation. The implications of the study to the present context is important as it shows that the manager will have to adopt solutions that satisfy at least two of these three needs in order to help employees reach a state of integrated regulation.

\section{Identification of Solutions}

\subsection{Providing a Meaningful Rationale}

The manager can share feedback from customers that were happy about the quality of the CDS pricing data and as a result had either renewed or signed contracts with the firm. This lets the employees understand that doing BAU work has helped to bring in revenue to the firm, providing a meaningful reason to do these tasks well. Also, the manager can explain to the employees that doing BAU work involves great attention to detail. Being meticulous is an important skill used by managers in writing specific, measurable, achievable, realistic, and timely (SMART) goals in their strategy plans regarding the future direction of the division. Thus, the employees' need for competence would most likely be satisfied.

\subsection{Conveying Choice Rather Than Control}

To facilitate a less controlling environment, the manager should refrain from verbally reminding employees to do BAU work too frequently. The manager should instead, suggest employees set their own calendar alerts to remind them of the task. This gives the employees a sense of autonomy, which as found in the research by Deci et al. (1994) should allow for employees to integrate BAU work values as their own.

\subsection{Acknowledging the Employee's Perspective}

As suggested by Deci et al. (1994) the manager can praise the employees when they have not made any errors. In the team meetings, the manager can also acknowledge that doing BAU work is uninteresting to the employees by saying the following (adapted from Deci et al. (1994)):

"Most of you have told me that doing BAU work is not fun. I understand your feelings and accept that these are not the most interesting of tasks."

By fostering a positive connection between the manager and employees, it is hoped that their need for relatedness will be met.

\subsection{Implementation Plan}

In the next three months, the manager should as a base, refrain from frequently berating employees to perform BAU work. Further, the manager should acknowledge that doing BAU work is uninteresting in the team meetings, and praise the employees when BAU work is performed well and inform them about satisfied clients that have signed up for the firm's products as a result of the BAU work. This would meet the autonomy, relatedness and competency needs of employees.

To test for the effectiveness of these solutions on how much the employees have internalized doing BAU work, the manager can see if there are improvement in satisfaction scores in future EES, reduction in number of errors committed by the employees and increase in the Team's retention rates.

\section{Conclusion}

While performing BAU work is uninteresting to the employees, these tasks are crucial in ensuring a high quality of CDS prices conveyed to clients that help to retain existing clients and bring in new deals to the firm. While ET suggests that the employees would be motivated to perform the tasks well due to the linking of these tasks to good performance appraisal and financial remuneration, this offers adopted controlled motivation at best. While CET can enhance extrinsic motivation with financial compensation, it does so at the risk of reducing intrinsic motivation. SDT thus offers the most applicable solution as it addresses the employees' need for autonomy, competence and relatedness, thus allowing employees to fully internalise BAU values as their own. In adopting the solutions proposed by SDT, it is hoped that employees will be happier in their job and stay with the firm, resulting in greater operational productivity.

\section{References}

Amabile, T. M., DeJong, W., \& Lepper, M. R. (1976). Effects of externally imposed deadlines on subsequent intrinsic motivation. Journal of Personality and Social Psychology, 34(1), 92-98.Available at: https://doi.org/10.1037/0022-3514.34.1.92.

Butcher. (2015). The 20 most desirable jobs in global finance. Retrieved from: http://static 1.businessinsider.com/the-20-most-desirablejobs-in-global-finance-2015-6.

Dec, E. L., Koestner, R., \& Ryan, R. M. (1999). A meta-analytic review of experiments examining the effects of extrinsic rewards on intrinsic motivation. Psychological Bulletin, 125(6), 627-626.Available at: https://doi.org/10.1037/0033-2909.125.6.627.

Deci, E. L. (1975). Intrinsic motivation. New York: Plenum. 
Deci, E. L., Ryan, R. M., Gagné, M., Leone, D. R., Usunov, J., \& Kornazheva, B. P. (2001). Need satisfaction, motivation, and well-being in the work organizations of a former eastern bloc country: A cross-cultural study of self-determination. Personality and Social Psychology Bulletin, 27(8), 930-942.Available at: https://doi.org/10.1177/0146167201278002.

Deci, E. L., Eghrari, H., Patrick, B. C., \& Leone, D. R. (1994). Facilitating internalization: The self-determination theory perspective. Journal of Personality, 62(1), 119-142.Available at: https://doi.org/10.1111/j.1467-6494.1994.tboo797.x.

Deci, E. L., \& Ryan, R. M. (2000). The" what" and" why" of goal pursuits: Human needs and the self-determination of behavior. Psychological Inquiry, 11(4), 227-268.Available at: https://doi.org/10.1207/s15327965pli1104_02.

Deci, E. L. (1971). Effects of externally mediated rewards on intrinsic motivation. Journal of Personality and Social Psychology, 18(1), 105115.Available at: https://doi.org/10.1037/ho030644.

Edward, D., EL, Cascio, W., \& Krusell, J. (1975). Cognitive evaluation theory and some comments on the Calder and Staw critique. Journal of Personality and Social Psychology, 31(1), 81-85.Available at: https://doi.org/10.1037/ho076168.

Edward, D. E., \& Ryan, R. (1985). Intrinsic motivation and self-determination in human behaviour. New York: Plenum.

Gagné, M., \& Deci, E. L. (2005). Self-determination theory and work motivation. Journal of Organizational Behavior, 26(4), 33 1-362.Available at: https://doi.org/10.1002/job.322.

Grolnick, W. S., \& Ryan, R. M. (1989). Parent styles associated with children's self-regulation and competence in school. Journal of Educational Psychology, 81(2), 143-154.Available at: https://doi.org/10.1037/0022-0663.81.2.143.

Half, R. (2018). From salary to work-life balance: What motivates Singaporean workers, press release. Retrieved from https://www.roberthalf.com.sg/sites/roberthalf.com.sg/files/press-

release/SG_Robert\%20Half\%20Press\%20Release_employee\%20turnover.pdf [17 October 2019$].$

KPMG. (2018). KPMG in India's annual compensation trends survey 2018-2019. Retrieved from https://assets.kpmg/content/dam/kpmg/in/pdf/2018/04/KPMG-India-Annual-Compensation-Trends-Survey.pdf

Porter, L. W., \& Lawler, E. E. I. (1968). Managerial attitudes and performance. Homewood, IL: Irwin-Dorsey.

PwC. (2012). Millennials at work Reshaping the workplace in financial services. Retrieved from https://www.pwc.com/gx/en/financialservices/publications/assets/pwc-millenials-at-work.pdf

Sheldon, K. M., Elliot, A. J., Ryan, R. M., Chirkov, V., Kim, Y., Wu, C., . . Sun, Z. (2004). Self-concordance and subjective well-being in four cultures. Journal of Cross-Cultural Psychology, 35(2), 209-223.Available at: https://doi.org/10.1 177/0022022103262245.

Sujansky, J., \& Ferri-Reed, J. (2009). Keeping the millennials. New York: Wiley.

Vroom, V. H. (1964). Work and motivation. New York: Wiley.

Zuckerman, M., Porac, J., Lathin, D., \& Deci, E. L. (1978). On the importance of self-determination for intrinsically-motivated behavior. Personality and Social Psychology Bulletin, 4(3), 443-446.Available at: https://doi.org/10.1177/014616727800400317. 